This is the final pre-publication version of an article submitted to Children \& Society in December 2016

Published details:

Dornan, Paul (2017) 'Children, Poverty and the Sustainable Development Goals' in: $\underline{\text { Children \& }}$ Society Volume 31, Issue 2 March 2017 Pages 157-165

\title{
Children, poverty and the Sustainable Development Goals
}

\author{
Paul Dornan, Young Lives/ODID
}

\begin{abstract}
The Sustainable Development Goals (SDGs) came into force in January 2016, taking over from the Millennium Development Goals (MDGs). Significant human development progress has occurred in recent decades. Nevertheless the MDGs have been criticised not least for failing to prioritise inequality and gains for the poorest people. The SDGs create a much more comprehensive agenda and support many key child rights concerns. While SDGs reflect an important global consensus, their delivery depends upon national action.
\end{abstract}

\section{Introduction}

The Sustainable Development Goals (SDGs) came into force on 1st January 2016 (see UN, 2015). Sometimes called Global Goals, the SDGs succeed the Millennium Development Goals (MDGs), and represent the second, 15 year, stage of delivering on the Millennium Declaration (UN, 2000). The SDGs reflect a much changed world than when the MDGs were set in place in 2000.

Since the millennium there has been considerable economic growth in many countries, with many graduating from so called low to middle income status (see Khan, 19/5/2015). The world has the largest ever generation of young people, most of whom live in low and middle income countries (UNFPA, 2014). There is huge potential for a 'demographic dividend' for fast changing low and middle income countries given large numbers of young people. Equally there is a pressing need to provide economic, social and political opportunities for this generation. Wider access now exists in many countries to basic services, schooling and to social protection, and access to technology has increased. However, there is also high and entrenched economic and social inequality in many countries. Very significant numbers of children remain exposed to interpersonal and societal conflict, as well as the threats posed by climate change and unsustainable development.

The SDGs are expansive in scope and universal in application. The goals were agreed by the world's governments through the UN's General Assembly, with initial thinking framed by the work of the High Level Panel on the 2015 agenda co-chaired by leaders from Indonesia, Liberia and the UK (High level Panel, 2013). The panel proposed transformational shifts to support delivering the goals. Of these shifts the need for the goals to 'leave no one behind' has gained particular prominence. 
This article outlines first what the SDGs are, and key differences from the predecessor MDGs. Next, the article sets the goals in the context of a changing world which poses particular challenges for children and young people. The review then discusses key challenges to achieving the SDGs, with a particular focus on children growing up in low and middle income countries, rather than in higher income OECD countries. Although it should be noted that concepts like 'leave no one behind' surely have relevance for citizens and governments in high income countries.

At the time of writing it is too early to say what difference the SDGs will make. A particular challenge given the ambitious scale is accountability and traction. At this point, there is much to play for.

\section{From Millennium Development Goals to Sustainable Development Goals}

The Millennium Development Goals (MDGs) set goals to galvanise national and international action following the Millennium Declaration (UN, 2000) which captured a feeling of optimism. Eight goals ${ }^{1}$ were supported by 18 targets and a wider set of indicators. Much has been written on the successes and the limitations of the MDGs (eg. Hulme, 2009; Easterly 2009; Nayyar, 2013). They provide a simple to communicate vision of development and also helped to align the attention of international organisations. UN system organizations identify the MDGs as a success (see UN, 2015). Though, of course, there is no counterfactual evidence of which changes would have happened in their absence. The design of the SDGs reflects both changes in the wider world and a reaction to weaknesses of the MDG framework.

\section{Box 1: The Millennium Development Goals ${ }^{2}$}

\section{Goal 1: Eradicate Extreme Hunger and Poverty \\ Goal 2: Achieve Universal Primary Education \\ Goal 3: Promote Gender Equality and Empower Women \\ Goal 4: Reduce Child Mortality \\ Goal 5: Improve Maternal Health \\ Goal 6: Combat HIV/AIDS, Malaria and other diseases \\ Goal 7: Ensure Environmental Sustainability \\ Goal 8: Develop a Global Partnership for Development}

The Sustainable Development Goals (SDGs) cover the period 2016-2030. They reflect a more ambitious agenda than did the MDGs. While the MDGs (see box 1) were focused on human development in developing countries, the SDGs (see box 2 ) are universal and all countries will have to report on actions to meet the targets in their own countries - something to which richer countries will need to adapt. In the UK, for example, the Parliamentary International Development committee has raised concerns over the UK Government's decision to allocate responsibility for domestic commitments to the Secretary of State for International Development (International Development Committee, 2016, para 74).

Three changes in the SDGs are perhaps of particular relevance to children. Firstly, there is greater emphasis within the SDGs on dimensions which were missing in the MDGs. These include a more

\footnotetext{
${ }^{1}$ http://www.unmillenniumproject.org/goals/
}

${ }^{2}$ http://www.unmillenniumproject.org/goals/ 
comprehensive approach to gender equality encompassing child marriage (which usually affects girls) and other harmful practices, violence against women and girls, governance and environmental sustainability. Secondly, there is a greater recognition of inequality, by gender, and in economic and other human development terms. Most MDG targets recorded average progress rather than change for the most disadvantaged (see Melamed, 2012; Fehling et al, 2013), while the SDGs contain a commitment to disaggregate data (including by gender and age) which will help expose inequalities. There is also an explicit goal on inequality (goal 10). Finally, while the MDGs focused attention, in part, to social policy coverage, the SDGs direct more attention to outcomes. Combined, the goals now set out a comprehensive agenda for children which maps across to the nine clusters of children's rights set out in the UN Convention on the Rights of the Child (UNICEF, 2016a).

Alongside the goals and targets, transformative shifts have been suggested for the SDGs, which give a sense of priority. These shifts speak to the means to reach the goals. The term 'transformative shift' was coined by the High Level Political Panel (2013) and involved objectives to:

- 'leave no one behind' (by eradicating extreme poverty and extending basic rights to all);

- 'to put sustainable development at the core of development' (by addressing climate change and environmental loss);

- 'to transform economies for jobs and inclusive growth' (creating better jobs and livelihood opportunities);

- 'to build peace and effective, open and accountable institutions for all' (including to address violence and conflict); and

- 'to forge a new global partnership' (of solidarity and mutual cooperation).

These shifts were to be supported by a 'data revolution', where better data is intended to help track progress and empower citizens (High Level Political Panel, 2013).

Perhaps the key question is how the SDGs have traction? One of the noted benefits of the MDGs was to help harmonise the approach of UN bodies and other agencies. SDGs are also likely to have an effect on the funding priorities of donor agencies, but the relative role of Overseas Development Assistance (ODA) in many countries is falling. Responsibility for the universal approach lies at the national level. The High Level Political Forum ${ }^{3}$ (not to be confused with the High Level Political Panel) provides the platform for 'follow up and review' of activities by countries. Countries commit to report to the forum on national action. Since the goals are not justiciable, action depends on national buy-in and peer pressure.

Box 2: The Sustainable Development Goals 4

1. End poverty in all its forms everywhere

2. End hunger, achieve food security and improve nutrition and promote sustainable agriculture

3. Ensure healthy lives and promote well-being for all at all ages

${ }^{3}$ https://sustainabledevelopment.un.org/hlpf

${ }^{4}$ https://sustainabledevelopment.un.org/?menu=1300 
4. Ensure inclusive and equitable quality education and promote lifelong learning opportunities for all

5. Achieve gender equality and empower all women and girls

6. Ensure availability and sustainable management of water and sanitation for all

7. Ensure access to affordable, reliable, sustainable and modern energy for all

8. Promote sustained, inclusive and sustainable economic growth, full and productive employment and decent work for all

9. Build resilient infrastructure, promote inclusive and sustainable industrialization and foster innovation

10. Reduce inequality within and among countries

11. Make cities and human settlements inclusive, safe, resilient and sustainable

12. Ensure sustainable consumption and production patterns

13. Take urgent action to combat climate change and its impacts

14. Conserve and sustainably use the oceans, seas and marine resources for sustainable development

15. Protect, restore and promote sustainable use of terrestrial ecosystems, sustainably manage forests, combat desertification, and halt and reverse land degradation and halt biodiversity loss

16. Promote peaceful and inclusive societies for sustainable development, provide access to justice for all and build effective, accountable and inclusive institutions at all levels

17. Strengthen the means of implementation and revitalize the global partnership for sustainable development

\section{From extreme poverty to inequality}

Extreme poverty was central to MDG 1. Over the past two decades, the rate of extreme poverty has been falling and extreme poverty is becoming concentrated in particular countries. While extreme poverty rates are falling, concern over economic inequality within countries is rising.

Extreme poverty was initially defined in the MDGs as living on less than the equivalent of dollar per person per day. ${ }^{5}$ The SDGs continue to use the extreme poverty measure but add other indicators alongside. Chart 1 shows that, since 1990, extreme poverty rates have fallen fast since 1990, though much less fast in Sub-Saharan Africa.

\footnotetext{
${ }^{5}$ Subsequently rebased to $\$ 1.25$ and then most recently $\$ 1.90$ per person per day (adjusted across countries using purchasing power parities).
} 
Chart 1: Falling extreme poverty rates

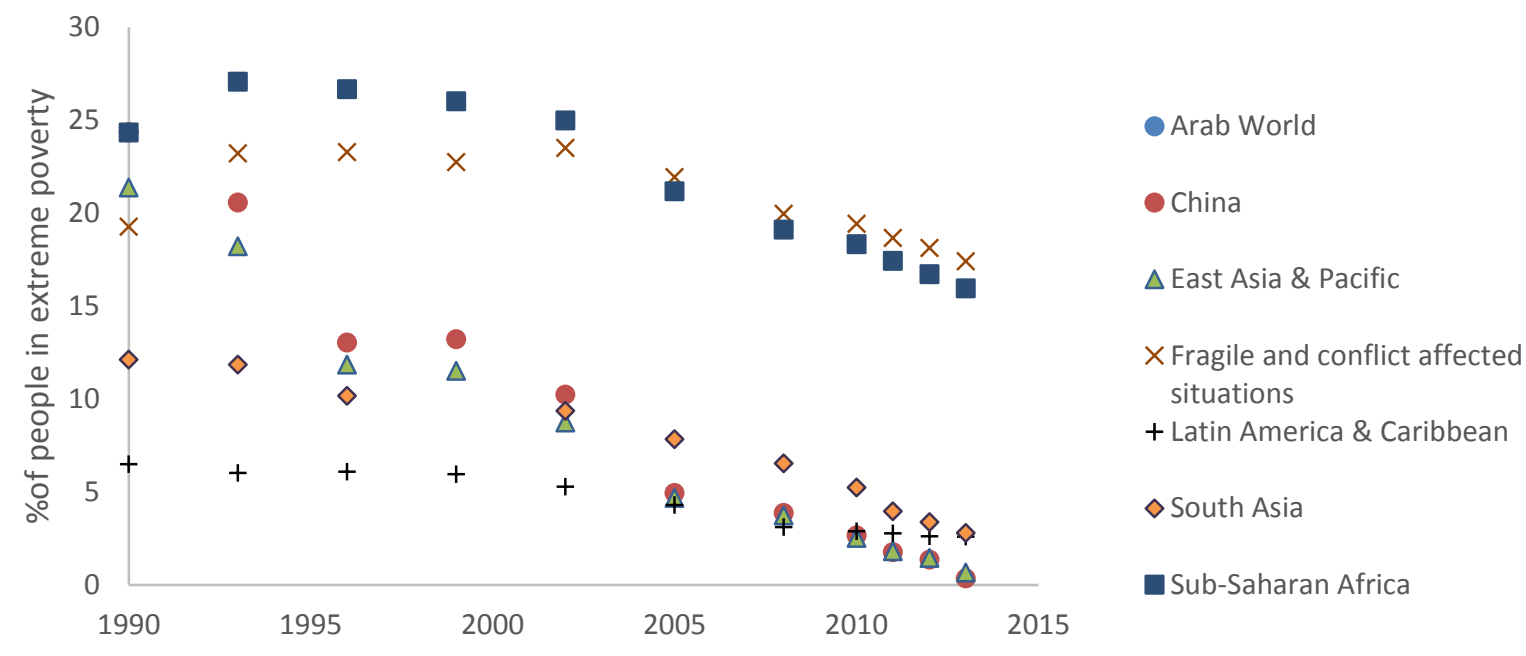

Source: $\underline{\text { http://databank.worldbank.org }}$

The most dramatic fall is seen in China. This reduction, combined with the large population, means that a large share of the global fall in extreme poverty comes from China. The lower rate of poverty reduction in low income countries (often in Sub-Saharan Africa), combined with population growth, actually means the absolute number of extreme poor people was slightly higher by 2010 than it had been in 1990 (Olinto et al, 2013).

The MDGs did not disaggregate the poverty target, relying on average change. Within the extreme poverty figures, it is now clear that children are over-represented. In 2013, of the 767 million extreme poor people, half (385) million were below 18 years of age (World Bank and UNICEF, 2016; Newhouse et al, 2016). The proportion of children who are poor is usually higher than the proportion of children in the population (see Table 1). Unchecked this over representation is expected to grow and become more focused in low income (usually African) countries (Watkins and Quattri, 2016).

Table 1: Comparing the share of people in poverty, and in the population by age

\begin{tabular}{|l|l|l|}
\hline Age group & \% of those in extreme poverty & \% of children in the population \\
\hline $0-4$ & 15.9 & 9.4 \\
\hline $5-9$ & 15.4 & 9.0 \\
\hline $10-14$ & 12.9 & 8.6 \\
\hline $15-17$ & 3.0 & 5.1 \\
\hline $18-59$ & 44.0 & 57.6 \\
\hline $60+$ & 5.8 & 10.3 \\
\hline
\end{tabular}

Source: World Bank and UNICEF, 2016

The notion of 'dollar a day' poverty directs attention to the poorest countries. Yet three quarters of extreme poor people actually live in so called middle income countries (Sumner, 2010). So, extreme poverty indicates not only differences between countries but within country inequality. Growing 
attention is consequently needed to taxation and redistribution (Hoy and Sumner, 2016), with key policy measures including the expansion of social protection (see Hanlon et al, 2010).

There has also been increasing recognition of the limits of the extreme poverty measure. While the measure is kept in SDG target 1.1, a second target sits alongside it:

By 2030, reduce at least by half the proportion of men, women and children of all ages living in poverty in all its dimensions according to national definitions (target 1.2)

Target 1.2 recognises the importance of disaggregation of average poverty rates. It also involves national definitions. This change increases the emphasis on multidimensional and relative poverty measures. In addition, the SDGs include a focus on inequality in goal 10. This is (partly) to be measured by the growth in incomes of the poorest $40 \%$ of the population (following the World Bank's commitment to shared prosperity, see World Bank, 2016).

In summary, over the period before and during the MDGs, extreme poverty rates fell. The majority of the extremely poor people now live in middle income countries, but longer term predictions suggest a future concentration of extreme poverty in Africa. Children are much more likely than other age groups to be poor. The SDGs reflect changes in how poverty is thought about and defined. There is some recognition of the considerable limitations to the extreme poverty measure. Therefore, targets are now to be age disaggregated, and there is increasing emphasis on other definitions, beyond extreme poverty.

\section{From policy coverage to quality and outcomes}

Over the period of the MDGs there have been notable gains. Coverage of basic services and systems has increased, but such coverage has not always translated into improved quality and outcomes. There remain stark differences in life chances between and within regions and countries. This section uses two important examples targeted by the MDGs (mortality and schooling). These examples are important in themselves but show wider concerns over progress, data and inequalities.

First, the good news. Over recent decades a number of positive trends have happened in MDG target areas (see UN, 2015). Chart 2 shows data on child mortality from 1990-2015. At the start of the period 12.7 million children died each year. By the end of the period the number of deaths had fallen to 5.9 million (UNICEF/WHO/World Bank, 2015). That more children survive is tremendous news. But many of the 5.9 million deaths were preventable and survival remains a lottery of birth. UNICEF record, for example, that 4 children out of 1,000 live births died by the age of 5 years in the UK. This compares with an average of 83 deaths for the whole of sub-Saharan Africa (UNICEF, 2016b, table 10).

But three further points are worth drawing out from Chart 2. First these are estimates, as there is a lack of vital individual level population reporting in many low and middle income countries (Byass, 2016; Lui et al 2016). So, inadequate data remains a barrier. Second, average figures mask variations within regions and within countries. In Niger, for example, Save the Children report a child born in the geographic region with the highest mortality rate was nearly five times more likely to die before 5 than a child born in the region with the lowest death rates (Save the Children, 2015). And third, while there has 
been an average reduction in child mortality, the proportion of infant deaths has increased (UNICEF/WHO/World Bank, 2015) suggesting that the problem (and solutions) is changing.

Chart 2: Estimated child deaths (under 5 years), 1990-2015

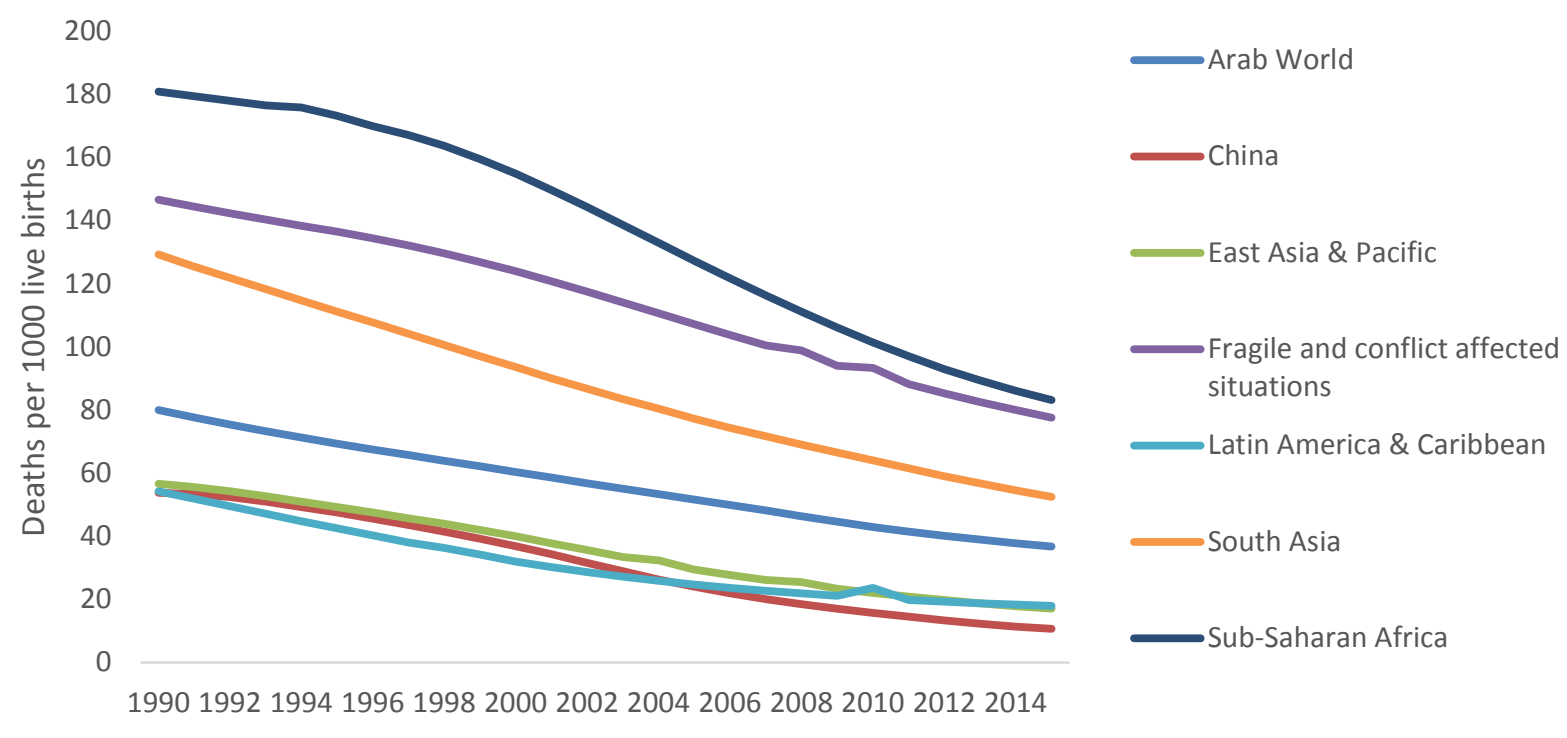

Source: http://databank.worldbank.org

A somewhat similar story of definite gains, but with serious limits, is shown by figures for net school enrolment in Chart 3. There is convergence towards universal enrolment across regions but many children remain out of school. UNESCO suggests that around 59 million children of primary school age were not enrolled in 2013. Girls were most likely to be missing out. UNESCO highlights particular concern over children affected by conflict, disabled children and those from minority ethnic backgrounds (UNESCO, 2015).

The figures in Chart 3 show the growing role of school within children's lives (attested to in other research eg. Pells and Woodhead, 2014; Winter, 2016), however the figures show a partial picture. The chart shows enrolment, but not whether children are actually turning up to school or whether children learn much when they do. While such conclusions vary between educational systems, UNESCO has identified what it terms a global learning crisis, arguing a

crisis in quality learning is evident. Despite increased enrolments, an estimated 250 million children cannot read, write or count well, whether they have been to school or not. $(2013$, p2)

The SDGs contain a stronger focus on learning, than did the MDGs, with reference made to both quality and to learning outcomes in underlying targets. These changes matter, not least since the rising role of schooling within children's lives implies promise that this will lead to social mobility and new life chances (Boyden, 2013). Yet in many countries both the quality of education and the availability of jobs remains a barrier (World Bank, 2012). A major challenge for the SDGs will be whether or not the promise of education can be made good. 
Chart 3: Rising net primary school enrolment, various regions 2006-2015

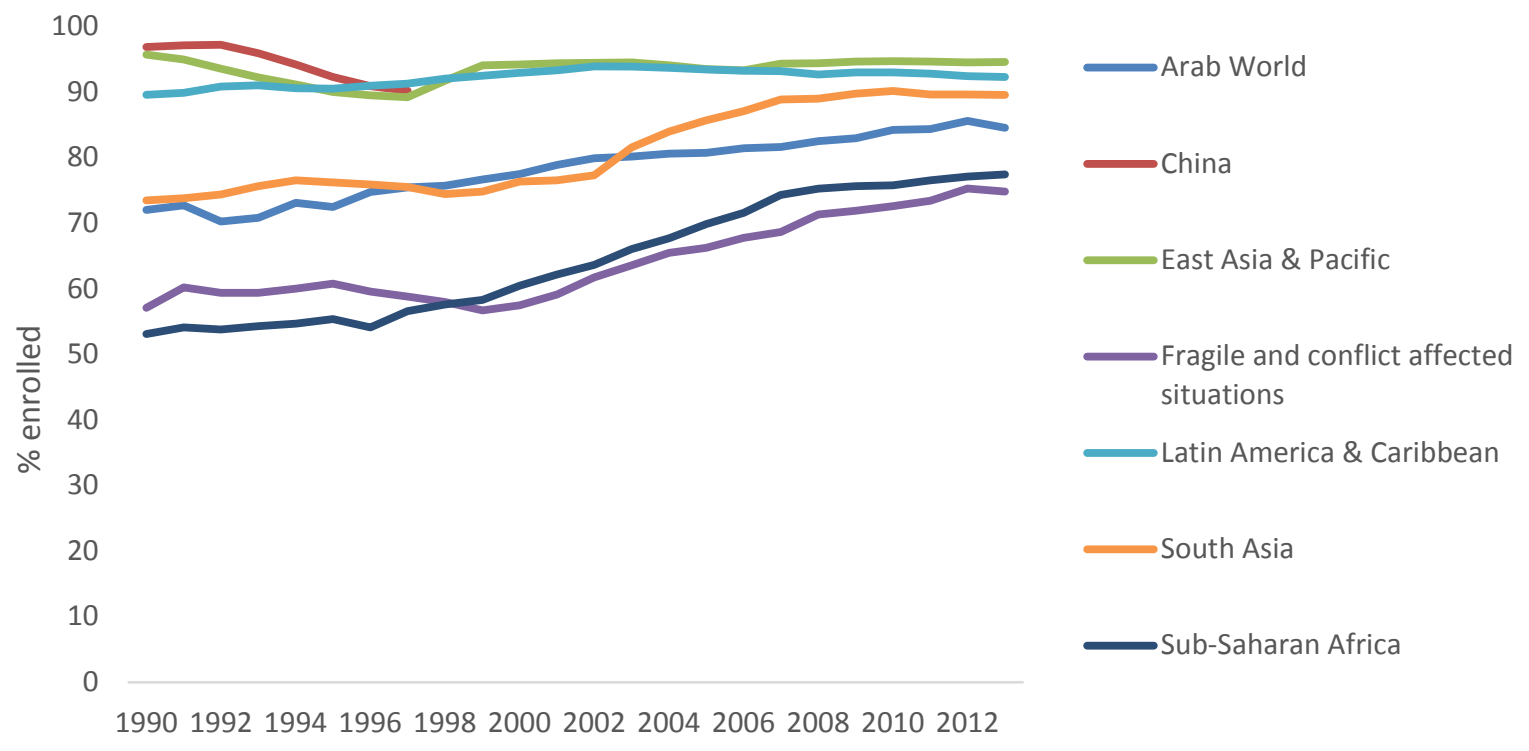

Source: http://databank.worldbank.org

There is much unfinished business from the MDGs: of preventable deaths, of a lack of decent services and of school enrolment. There is also a data challenge. In the cases noted there was lack of civil registration which undermines tracking and targeting the problem. For schooling, the MDG enrolment figures are useful but do not show much about learning, or indeed attendance. There is a considerable equity challenge. The SDGs promise data disaggregation and the principle of 'leave no one behind'. Both are welcome. Operationalising how progress for the most marginalised within society will be targeted is an important challenge. And finally, there is a task to build on the gain in social policy coverage and move towards the quality of services and their outcomes in improvements in children's life chances. For children a life course approach is helpful to inform action (see Dornan and Woodhead, 2015).

\section{Conclusion}

The article ends with five summary conclusions.

First, a rising tide of economic growth has not lifted all boats. Economic growth is an important contributor to both personal opportunities and national fiscal space. But growth is no guarantee of an end to poverty. There has been economic growth in many poorer countries since 2000 and many countries have graduated from low to middle income status while their populations continue to experience low standards of living and high inequality. Most acutely worrying is the number of children affected by conflict and state fragility.

Second, children are more likely to be poor. The latest figures show half of those in extreme poverty are children. Goal 1 uses both extreme poverty and national definitions. The use of national definitions encourages more relative and multidimensional measures, accepting a wider sense of how poverty affects children. Since the SDGs require age disaggregation, children's over-representation among poor people will become clearer. 
Third, within the SDGs there is much greater recognition both of the problem of economic, gender and social inequalities than there was in the MDGs. Such disparities are a barrier not only to equity but to the achievement of the SDGs. Greater data disaggregation and tracking is an important feature for shedding light on the experiences of the most disadvantaged people. The mandate to leave no one behind' is relevant for higher income and not just for low and middle income countries.

Fourth, the quality as well as the coverage of social policies for children is a concern. In recent decades in many low and middle income countries social policy systems have expanded. While barriers remain, girls and boys are often experiencing greater access to schooling, health care, basic services and social protection. It is, of course, both challenging and misleading to try to tell a global story of such national complexity. But perhaps the key conclusion is that it is not a given that rising access translates to quality. The SDGs also create a welcome shift from inputs such as school enrolment towards the outcomes of services such as learning.

Finally the world of the Sustainable Development Goals is very different to that of the Millennium Development Goals. Social policy systems have expanded in many low and middle income countries. This expansion has often been funded by national resources not ODA. While the MDGs were directed at human development in developing countries, the SDGs are universal in remit. While the SDGs reflect a global framework, the keys to unlocking success remain with national delivery.

\section{References}

Boyden, J, 2013, 'We're not going to suffer like this in the mud': educational aspirations, social mobility and independent child migration among populations living in poverty, Compare, Volume 43, 2013 - Issue 5

Byass, P, November 10, 2016, Child mortality is (estimated to be) falling, The Lancet, Online first Dornan, P and Woodhead, M, 2015, How Inequalities Develop through Childhood, Florence: UNICEF Office of Research

Easterly, W, 2009, How the Millennium Development Goals are Unfair to Africa, World Development, Volume 37, Issue 1, January 2009, Pages 26-35

Fehling, M, Nelson, B, and Venkatapuram, S, 2013, 'Limitations of the Millennium Development Goals: a literature review', Global Public Health Vol. 8, No. 10, 1109-1122

Hanlon, J, Barrientos, A and Hulme, D (2010), Just give money to the poor: The development revolution from the Global South, Kumarian Press

High Level Political Panel, 2013, A new global partnership: eradicate poverty and transform economies through sustainable development, The Report of the High-Level Panel of Eminent Persons on the Post2015 Development Agenda, New York: United Nations

Hoy, C, and Sumner A, 2016, Global Poverty and Inequality: Is there new capacity for redistribution in developing countries? Journal of Globalization and Development 
Hulme, D, 2009, The Millennium Development Goals (MDGs): A Short History of the World's Biggest Promise, Manchester: Brooks World Poverty Institute, Working paper 100

International Development Committee, 2016, UK implementation of the Sustainable Development Goals First Report of Session 2016-17 House of Commons

Khan, T, 19/2/2015, Growing up: graduation from low-income to middle-income status, Lets talk development blog, World Bank http://blogs.worldbank.org/developmenttalk/growing-graduation-lowincome-middle-income-status

Liu, L Oza, S, Hogan, D, Chu, Y, Perin, J, Zhu, J, Lawn, J, Cousens, S, Mathers, C, Black and R, November 10, 2016, Global, regional, and national causes of under-5 mortality in 2000-15: an updated systematic analysis with implications for the Sustainable Development Goals, The Lancet, Online first

Melamed, C, 2012, Putting inequality in the post-2015 picture, London: Overseas Development Institute

Nayyar, D, 2012, The MDGs after 2015: Some reflections on the possibilities, New York: UN system task Team on the Post-2015 UN development agenda

Newhouse, D, Suarez-Becerra, P, Evans, M with Data for Goals group, 2016, New Estimates of Extreme Poverty for Children, Policy Research Working Paper 7845 Washington: World Bank

Olinto, P, Beegle, K, Sobrado, C and Uematsu, H, 2013, The State of the Poor: Where Are The Poor, Where Is Extreme Poverty Harder to End, and What Is the Current Profile of the World's Poor?, Washington: World Bank

Pells, K and Woodhead, M, 2014, Changing Children's Lives Risks and Opportunities, Oxford: Young Lives

Save the Children UK, 2015, The lottery of birth: Giving all children an equal chance to survive, London: Save the Children

Sumner, A, September 2010, Global Poverty and the New Bottom Billion: What if Three-Quarters of the World's Poor Live in Middle-Income Countries? Brighton: IDS Working paper

UNESCO, 2013, The global learning crisis, why every child deserves a quality education, Paris: UNESCO

UNESCO, 2015, A growing number of children and adolescents are out of school as aid fails to meet the mark, Paris: UNESCO

UNFPA, 2014, The power of the 1.8 billion: adolescents, youth and the transformation of the future, The State of the World's population 2014, UNFPA

UNICEF, WHO, World Bank and UN, 2015, Levels \& Trends in Child Mortality Report 2014, Estimates Developed by the UN Inter-agency Group for Child Mortality Estimation

UNICEF, 2016a, Mapping the Sustainable Development Goals and the Convention on the Rights of the Child, UNICEF: New York 
UNICEF, 2016b, The State of the World's Children 2016, UNICEF: New York

United Nations (UN), 2000, United Nations Millennium Declaration, New York: United Nations General Assembly, fifty-fifths session

United Nations (UN), 2015, The Millennium Development Goals Report 2015, United Nations: New York

United Nations (UN), 2015, Transforming our world: the 2030 Agenda for Sustainable Development, New York: United Nations General Assembly

Watkins, K and Quattri, M, 2016, Child poverty, inequality and demography: Why sub-Saharan Africa matters for the Sustainable Development Goals, London: ODI

Winter, F, 2016, Shaping Aspirations and Outcomes: Gender and Adolescence in Young Lives, Oxford: Young Lives

World Bank, 2012, World Development Report 2013: Jobs, Washington, DC: World Bank.

World Bank, 2016, Poverty and Shared Prosperity: Taking on inequality, Washington: World Bank

World Bank and UNICEF, 2016, Ending Extreme Poverty: a focus on children, World Bank and UNICEF 